\title{
MELHORAMENTO DO MILHO DOCE (Zea maz saccharata Stu.)
}

\author{
MARIO P. MEZZACAPPA \\ Secção de Genética
}

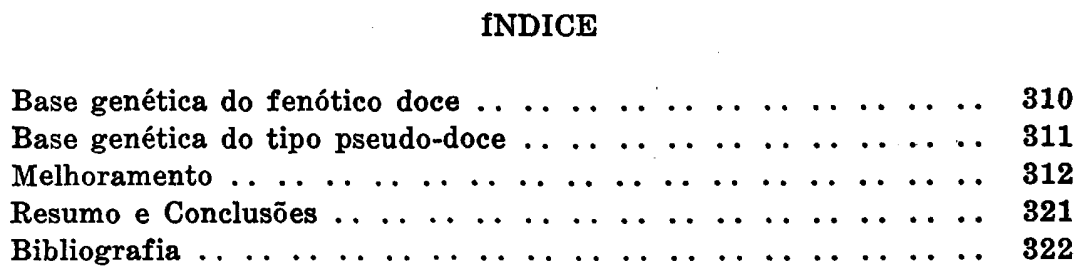




\section{BASE GENÉTICA DO FENÓTIPO DOCE}

O gen recessivo su1 descoberto por CORRENS em 1901, e posteriormente localizado no quarto cromossoma, é o principal responsável para impedir a transformação dos açúcares e dextrinas em amido.

EYSTER, em 1934 segundo EMERSON, BEADLE e FRASER (1), descobriu e localizou um outro gen para doce, su2, no cromossoma seis. Êsse gen, quando homozigoto recessivo, determina um endosperma que varia de translúcido a opaco, podendo o grão ser nu não enrugado.

O gen su3, também encontrado pelo mesmo autor. está localizado no cromossoma nove e apresenta efeito semelhante ao su2.

HOROVITZ, MARCHIONI e FISHER, (2) em 1943 encontraram em uma variedade de milho pipóca da província de Corrientes, na República Argentina, um gen que denominaram iniciaimente sux que apresenta efeito semelhante ao su2. Ambcs estãc localizados no cromossoma seis; o gen sux, posteriormente, foi identificado como sendo o mesmo su2.

Esse gen, quando homozigoto, interage com sul, invertendo sua dominância e tendo os seguintes efeitos :

\section{QUADRO 1}

\begin{tabular}{|c|c|c|c|}
\hline Constituição Su? & Constituiçăo Su1 & Fenótipo & \% Açúcares \\
\hline su2 su2 su2 & $\begin{array}{l}\text { Su1 Su1 Su1 } \\
\text { Su1 Su1 su1 } \\
\text { Su1 su1 su1 } \\
\text { su1 su1 su1 } \\
\end{array}$ & $\begin{array}{l}\text { Opacc. } \\
\text { Enrugado } \\
\text { Enrugadc } \\
\text { Enrugad. }\end{array}$ & $\begin{array}{l}3,22 \\
4,80 \\
13,80 \% \\
\text { super-doce }\end{array}$ \\
\hline Su2 Su2 Su? & ${ }_{\text {su1 su1 }}^{\text {Su1 }} \overline{\text { s:1 }}$ & $\begin{array}{l}\text { Opaco } \\
\text { Enrugade }\end{array}$ & 5,14 \\
\hline
\end{tabular}

MANGELSDORF e REEVES (3) citados por EMERSON 1935), descreveram um outro tipo de milho doce, ac qual cenominaram "doce-amiláceo", devido a um novo aléle sulam su1am, semelhante ao tipo su1 su1, só que os grãos são menos enrugados e translúcidos que o doce comum, principalmente na metade inferior da semente. 
O novo tipo de endosperma doce foi chamado doce-amiláceo por lembrar em seus aspectos gerais a desciição e ilustração de uma variedade de milho doce que STURTEVANT em 1887, denominou Zea amileasaccharata ou doce-amiláceo.

MANGELSDORF (4) admite que dois gens especiais $\epsilon$ stão envolvidos na herança do doce-amiláceo. Um dêles, chamado "dull", du por ter apresentado em algumas progênies uma aparéncia escura na semente. $O$ outro, suam é um alélo de su1. Assim, o doce-amiláceo tem uma composição genética suam su am dudu; o doce normal é susu DuDu enquanto o amiláceo comum é SuSu DuDu. O efeito de qualquer recessivo isoladamente não é distinguível visualmente, embóra a segregação para "dull", possa ser visível em alguns casos $O$ efelto conjunto dos dois recessivos produz o doce-amiláceo que por sua vez é fàcilmente distinguível dos tipos amido e doce comum.

O gen du também tem efeito sôbre o aléle su1 eumum, pois de cruzamentos de doce susuDuDu, e doce-amiláceo. suam suam dudu podemos isolar super-doce sul suldudu, e pseudo-doce suam suamDuDu, como vemos no quadro abaixo:

Análise química de diversas constituições de milho doce. Modificado de MANGELDORF.

Comparando-se os quadros 1 e 2, vemos que o super-doce de HOROWITZ é muito mais rico em açúcares que o de MANGELSDORF e REEVES, principalmente se levarmos em conta que $13,80 \%$ é a análise de uma mistura de super-disce de constituição su1 su1 su1 su2 su2 su2, com doce de genótipo Su1 sia1 su1 su2 su2 su2, pois, pelo fenótipo não se consegue separar êsses dois genótipos.

\section{BASE GENÉTICA DO TIPO PSEUDO-DOCE}

JONES em 1919 foi o primeiro a estudar a base genética dêste importante defeito do milho doce e tantu êle como HARPER 1920, citados por MATSUURA (5), verificaram que o fenótipo pseudo-doce é apenas uma variante du genótipo su1 su1 su1 e não dos tipos Su1-. JONES postulou a existência de três fatôres : o gen dominante $M$ da planta mãe, sendo o efeito de MM mais pronunciado que o de $\mathrm{Mm}$; o gen dominante $\mathrm{N}$ do endosperma, mostrando efeito de dosagem inibindo c enrugamento e finalmente o gen dominante 0, que torna os grãos opacos.

Os resultados dos trabalhos da Secção de Genética ainda não publicados, iniciados em 1937, estão de acôrúc com JONES 
no seguinte: Há gens da planta-mãe assim como do endosperma causando o fenótipo pseudo-doce, apezar da homczigotia do gen sul. Porém, a situação se torna mais comp̣icada, pois o número de gens modificadores deve ser superior a 3 Além disso foi verificado experimentalmente, em descendentes de cruzamentos com raças de Cateto, que a porcentagem de grãos pseudo-doces aumenta quando selecionamos para a coloração laranja intensa do endosperma. $O$ efeito provàvelmerte é devido à gens ligados aos fatôres para coloração, pois podemus, por seleção contínua, quebrar a ligação. E' inteiressante not.ar que os gens para coloração forte do endosperma tem efeito também sôbre o contraste mole-duro do endosperma.

\section{MELHORAMENTO}

A primeira vista parece ser muito simples a obtenção e melhoramento do milho dôce, pois há um gen principal recessivo sul que determina êsse carácter. A simples seleção de material homozigoto para êsse gen resolveria o problema, sendo aper:as necessário eliminar os fatôres para pseudo-ạçicares.

Entretanto, convém frizar que há grande variação entre as diferentes raças homozigotas, para sul, porquanto dif $\in$ rem grandemente em suás constituições genéticas. Além dissc, devemos considerar que sempre que iniciamos um trabalho de melhoramento, devemos ter em mente as exigências do mercado e da lavoura, ou em outras palavras, conciliar os interêsses dos compradores e produtores.

Em nosso país os problemas de melhoramento podem ser resumidos em dois grupos: Problemas gerais, aue são us mesmos em tôdas as regiões em que se pretende cultivar o milho

Problemas Particulares, que surgem em nosso país.

Problemas gerais - Neste grupo incluimos certas características agronômicas importântes relacionadas às plantas e espigas.

O critério a ser seguido é escolher as melhores plantas e espigas, e entre éstas, as que apresentam melhor tipo de grãos.

As melhores plantas são aquelas que possuem as seguintes características : coloração verde intensa; vigorosas; resistentes às pragas e moléstias e ao acamamento; não muito altas; espigas bem localizadas sôbre o calmo; finalmente, o sistema radicular e a flexa ou pendão bem desenvolvidos. 


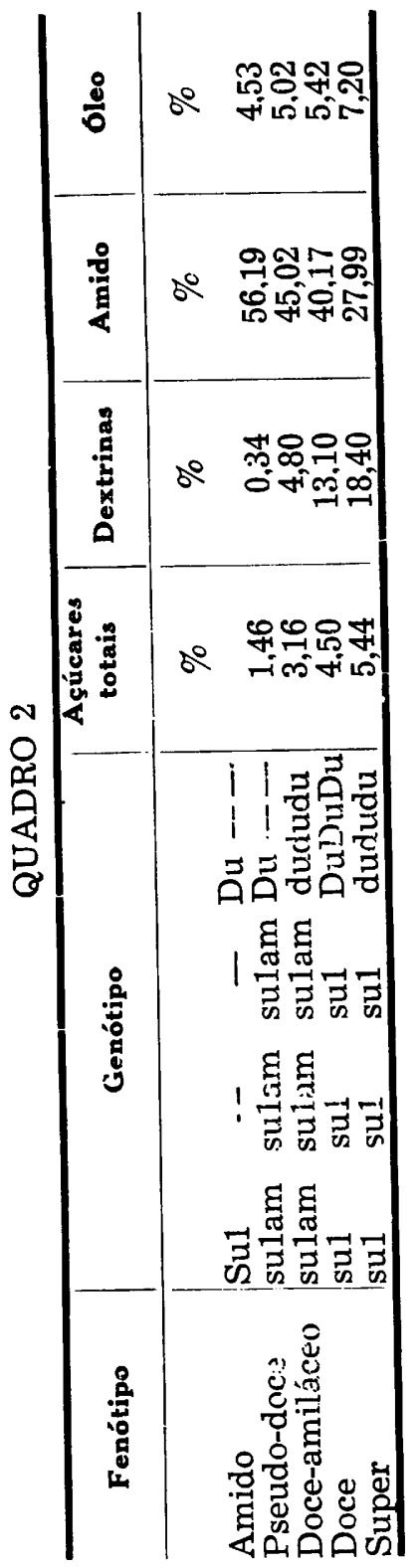


Em milho dôce a unidade para efeitos comerciais é a espipiga, devendo portanto merecer especial atenção. Assim devein ser cilíndricas, de fileiras retas, bem granadas e sem grãos pseudo-açúcares.

Outro fatôr importânte que não devemos esquecer nos trabalhos de melhoramento é a resistência à lagarta da espiga, Laphigma frugiperda.

Em nossas populações dôces P-678 e P-18, cultivadas sucessivamente desde fins de setembro até natal, verificámos um ataque pequeno, isto é, no máximo uma lagarta na ponta da espiga. Essa baixa infestação, segundo tudo indica, não depende da natureza e comprimento da palha. Atribuimos êste resultado à rigorosa seleção do material usado na colheita e antes da semeadura, pois, são eliminadas tôdas as espigas que apresentam o mais leve sinal de infestação.

CUTLER (6), verificou que muitos tipos comerciais e indígenas de milho sulamericano apresentam um pedúnculo ou ráquila muito longa prendendo os grãos do sabugo; ele julga interessante tomar em consideração essa característica, em trabalho de' melhoramento, pois em tais tipos, quando as espigas são consumidas, as glumas se prendem entre os dentes. As observações feitas em Piracicaba nêsses últimos 15 anos estão perfeitamente de acôrdo com êsse ponto de vista.

Um fatôr de importância relativa é a coloração dos grãos, pois devemos sempre produzir o tipo preferido pelo mercado consumidor. $\mathrm{Na}$ república Argentina, por exemplo, dá-se preferência ao tipo branco; nos Estados Unidos, Perú e Brasil, os consumidores preferem os coloridos de amarelo forte.

Em se tratando de variedades coloridas, de amarelo a coloração pode dar um indício de maturação da espiga; assim, em P-18, variedade dôce cultivada na Secção de Genética da E. S. A. "Luiz de Queiroz", que contém um fatôr Bn para coloração crême da aleurona, o aparecimento dessa côr indica que a espiga já está "passada". Em tipos dôces com endosperma de coJoração amarela, um amarelo muito leve indica que a espiga madura, ao passo que amarelo mais intenso nos revela que a espiga já "passou".

Existem fatôres importantes, tais como textura e consistência dos grãos, qualidade e quantidade de açúcares, maturação, etc., que devem ser levados em consideração em qualquer plano de melhoramento do milho dôce.

A fim de mostrar a importância dessas características citaremos a seguir alguns trabalhos relacionados ao assunto. 
RUDWICK and BAKE (7), idealizaram um método para testar a resistência do pericarpo que consta do seguinte : retira-se o pericárpio de alguns grãos e coloca-se em um pedaço de cortiça; determina-se a sua consistência, em função da maior ou menor resistência à penetração de uma agulha de vidro que se acha presa a uma balança de Joly. Êsse método além de ser muito trabalhoso, deixa muito a desejar.

CULPEPPER and MAGON (8) usaram um novo processo, mais fácil e seguro para testar a consistência ao pericárpio, que é baseado na resistência à penetração de uma agulha colocada sôbre o grão e pressionada por uma mola.

DOXTATOR (9), relatou que certas linhagens de grãos tenros transmitem essa propriedade a seus hibridos.

ANDREW, BRINK and NEAL (10) estudando a genética da espessura do pericárpio observaram que a consistência (resistênciz à penetração da agulha) dos grãos dôce-cerosos (sugary-waxy) era maior quando se utilizava na polinização polem de plantas amido-cerosa e amido-não cerosa.

DOXTADOR (9) menciona não haver diferença quanto a espessura do pericárpio em linhas descendentes de híbridos simples da variedade Colden Bantan.

GANGSTAD e SNELL (11), notaram que a consistência do pericárpio aumenta em progressão linear com o grau de maturação do grão. Observaram ainda, diferenças significantes entre diferentes linhagens e entre diferentes variedades. Mostraram mais, que é possível à base da textura dos grãos das linhas autofecundadas, prevêr a textura dos grãos de seus híbridos.

A previsão do comportamento dos híbridos é dada por uma equação de regressão cujos coeficientes são as médias dos coeficientes das equações de regressões das linhas paternais como vemos no quadro abaixo.

DOTY, SMITH, ROACH, SULLIVAN, CAMERON e M.ANGELSDORF (12) mostraram haver diferenças no conteúdo de açúcares e na rapidês de maturação de diversas variedades e linhagens de milho doce.

SINGLETON (13) achou que essas observações abrem um campo muito importante nas questões de melhoramento ? que a análise do sabor em geral deveria ser elevada a efeito.

HARBER (14) sugeriu a possibilidade de serem aproveitadas qualidades desejáveis de milho dente, duro, farináceo e ceroso no melhoramento de linhas autofecundadas de milho doce. 


\section{QUADRO 3}

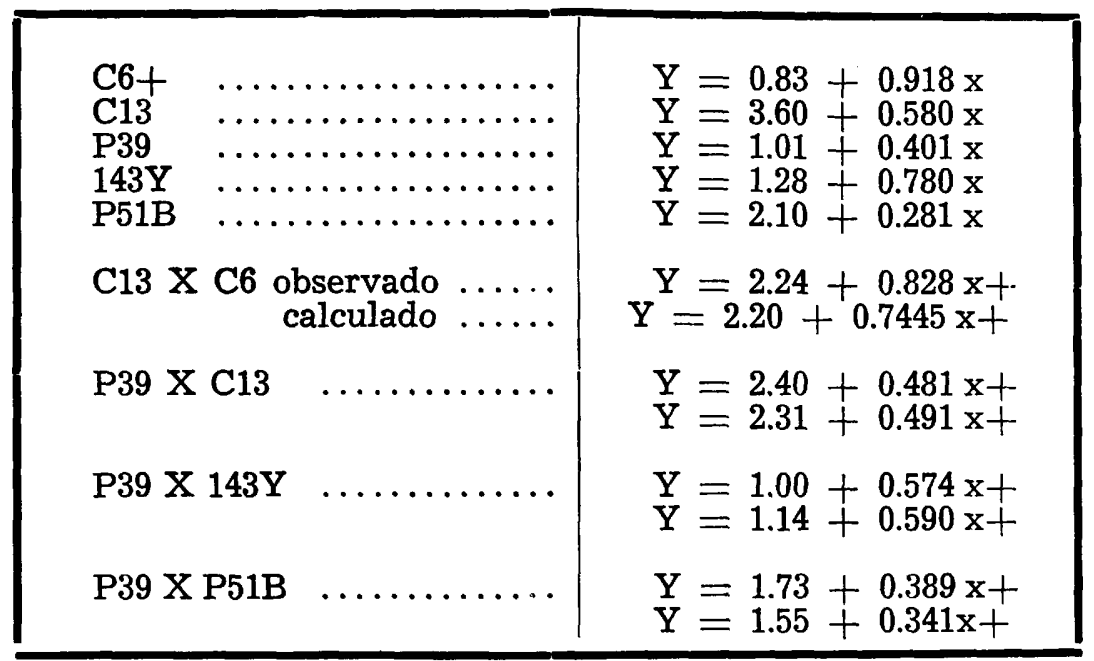

GALINAT e EVERETT (15) chamaram a atenção para a necessidade de se testar o sabor do milho doces, após mencionarem certos característicos a êle relacionados.

Freblemas particulares ao nosso clima - Um dos fatores principais, que segundo tudo indica impede a aclimatação entre nós de material dos Estados Unidos, Canadá ou de outras reregiões onde os dias são mais longos, é o fotoperiodismo, pois os dias em nosso Estado são mais curtos. Esta diferença no número de horas de insolação pode causar distúrbios fisiológicos às plantas, que muitas vêzes morrem antes de completarem 0 ciclo vegetativo e, devido a isso, as espigas não se desenvo!vem convenientemente e os grãos não chegam a maturidade.

No caso do milho as sementes colhidas, ainda, germinam relativamente bem, mas as plantas crescem fracas e poucas delas, pelas razões expostas chegam a produzir espigas razoáveis.

As plantas, muito baixas e perfilhadas, assim como as espigas também localizadas muito baixas sôbre o colmo, sãc fatores que contribuem para dificultar os tratos culturais e a colheita. Além disso, as espigas apresentam as palhas muito curtas, o que facilita o ataque por parte dos pássaros e insetos.

Outro defeito importante que deve ser eliminado durante os trabalhos de melhoramento é a presença de lâminas folhares nas paihas. 
Não sendo possivel obter diretamente, a partir de material importadu, aquilo que se deseja, devemos então procurar transferir o fator doce para as nossas variedades comerciais, para sua adaptação, o que se consegue por uma série de cruzamentos, retrocruzamentos e autofecundações.

\section{Milho Doce Piracicaba $-1^{\circ}$. ciclo}

Material e método - Em 1936, quando veio para o Brasil o prof. Brieger, trouxe uma pequena coleção de milho doce de várias procedências, principalmente norte-americano, entre os quais Golden Bantan, Banting, Golden Gem, etc., assim como vários híbridos.

Esse material não se comportou bem entre nós e todos os esforços para sua imediata aclimação foram negativos.

Entre os híbridos introduzidos comportou-se melhor o constituido por doce americano e um flint branco muito resistente, colhido originalmente no Tirol, na Autria.

Esse híbrido posteriormente foi cruzado, para adaptação, com tipos nacionais, dente Sta. Rosa e cateto, ambos da Fazenda Modêlo da E. S. A. "Luiz de Queiroz", da Universidade de São Paulo.

A geração S2 dêsse cruzamento foi reproduzida por polinização livre, anotando-se entretant,o o florescimento das plantas. Isso foi necessário devido à grande variação na época de florescimento; a polinização livre parecia o caminho mais razoável para se obter polinização só entre plantas da mesma precocidade, isto é, que floresciam na mesma época.

Posteriormente, durante 3 gerações o material foi autofecundado escolhendo-se apenas os indivíduos que apresentavam característicos agronômicas desejáveis.

Terminada essa fase de autofecundação, foram feitos híbridos entre as diversas linhagens; nos três anos seguintes foram levados a efeito cruzamentos entre os híbridos, eliminandc-se tôdas as combinações que não apresentavam vigor e não correspodiam em seus caracteres ao tipo padrão.

A seguir, as sementes de diversos híbridos múltiplos de características semelhantes foram misturadas, estabelecendo-se assim, 24 populações que foram cultivadas separadamente. Dessas populações que diferiam grandemente em sabor, doçura, textura dos grãos, rapidez de maturação, etc., após rigorosa seleção, foram eleitas apenas duas P-678 e P-18, ambas saborosas, dôces, com pericárpio fino e endosperma de textura delicada. P-678 possue pericárpio pouco mais expesso que a P-18. 
Ambos os sintéticos que apresentaram bôas caracteristicas agronômicas de planta e espiga estão sendo cultivados e rnantidos desde 1945 por seleção massal.

O comprimento das glumas, ainda, é variável em ambas as populações, de modo que estão sendo executados trabalhos no sentido de corrigir êsse defeito.

\section{Milho Doce Piracicaba $-2^{\circ}$. ciclo}

Descrevemos, resumidamente, a marcha utilizada na obtenção do milho doce, processo êsse elaborado e posto em prátíca na Secçäo de Genética da Escola Superior de Agricultura "Luiz de Queiroz", pelo prof. Brieger. Tal método se justifica pelas seguintes razões: a) necessidade de transferir gens para a adaptação do tipo doce às nossas condições; b) impossibilidade de se testar as capacidades geral e específica de combinação por não existirem naquela época variedades já aclimatałas. Uma vez obtidas variedades sintéticas com bôas caracteristicas agronômicas. poderiam ser elas submetidas ao melhoramento, obtendo-se assim variedades sintéticas do segundo ciclo mais produtivas ou híbridos simples, segundo os processos clássicos de melhoramento de milho.

mente reconhecível devido à coloração branca das hastes da

Os trabalhos de autofecundação e seleção, visando a obtenção de híbridos foram iniciados em 1945 e estiveram até 1950 a cargo do colega Dr. Nelson Kobal. Foram autofecundadas cêrca de 800 plantas dos diversos sintéticos então existentes.

A capacidade geral de combinação foi testada em S3 pelo processo do cruzamento linha-variedade, sendo polinizadas 3 plantas de cada linha com uma mistura de polen de 15 plantas dos sintéticos que deram origem as linhas submetidas à autofecundação.

As linhas eleitas à base dos cruzamentos linha $\mathrm{x}$ variedads: (top-crosses) foram posteriormente associadas em híbridos simples para se avaliar a capacidade específica de combinação.

Foram, assim obtidas, cêrca de 80 híbridos simples reunidos em 3 grupos de acôrdo com a coloração (branco, crême e laranja). As linhas assim eleitas, serão utilizadas na confecção de híbridos simples. Em milho doce, dá-se preferência ̀̀ hibridos simples, pois, além do consumo imediato, destina-se ainda ao enlatamentc, indústria que exige como características principais, grande uniformidade ná maturação e nas espigas

Além da produção de híbridos simples estamos também interessaclos na obtenção de novas variedades sintéticas de $2^{\text {n }}$. ciclo, trabalho êsse que está sendo executado paralelamente ao processo clássico de milho híbrido. 
Foram autofecundadas 200 plantas dos sintéticos P-18 e P-678 em 1951. Èste ano, 1953, testaremos a capacidade geral de combinações a fim de escolher as linhas que serão associadas nos sintéticos.

Como o isolamento de linhagens que apresentam hôas características agronômicas e que combinadas formam híbridos de alta produção tem constituido uma das mais sérias preocupações nos trabalhos de melhoramento, faremos, a seguir um breve resumo dos principais trabalhos relacionados ao assunto.

A princípio, atribuiu-se grande importância aos caracteres morfológicos e a produtividade das linhas durante o processo de autofecundação.

Assim, KIESSELBACK (16), RICHEY (17), RICHEY e MAYER (18), HAYES (19), NILSON-LEISSNER (20), JEORGENSON e BREWBACKER (21), JENKINS (22) e HAYES e JOHNSON (23), acharam haver correlação entre produção e certos caracteres morfológicos das linhas autofecundadas, e seus híbriảos.

Atualmente, na seleçâo das linhagens, além das características agronômicas desejáveis devemos levar em consideração as capacidades geral e específica de combinação.

Denominamos capacidade geral de combinação ao comportamento médio de uma linhagem em combinaçõ̃es híbridas. A capacidade específica de combinação tem por fim conhecer certas combinações especiais que podem ser superiores ou mesmo, inferiores, ao valor médio determinado pela capacidade geral de combinações.

No início dos trabalhos de melhoramento o teste da capacidade geral de combinação era baseado no comportamento médio de todos os possíveis cruzamentos simples entre elas. Essse processo, entretanto, é muito trabalhoso, de modo que tornou-se necessária a utilização de métodos mais simples.

Assim, foi proposto por RICHEY e colaboradores o emprêgo de linhagens testeres.

DAVIS (24) lançou mão do cruzamento linha $x$ variedade, ou top-cross, para avaliar a capacidade geral de combinação das linhagens.

JENKINS e BRUNSON (25) e JOHNSON e HAYES (26), comparando os diversos métodos de testar a capacidade de combinação, obtiveram dados que justificam o emprêgo do cruzamento linha $\mathrm{x}$ variedade na seleção das linhas autorecundadas.

Outro ponto, importante que até hoje constitue o pomo da discórdia entre inúmeros geneticistas e melhoristas de milho é a época em que se deve testar a capacidade geral de combina- 
ção, isto é, se no início do trabalho de homogeneisação (S: ou S1), ou mais tarde em S3 ou S4.

DAVIS (27), JENKINS (28), SPRAGUE (29), BROWN (citado por RICHEY (30), apresentam dados mostrando ser possível testar a capacidade geral de combinação logo no início do processo de autofecundação.

SINGLETON e NELSON (31) acharam ser impossível testar a capacidade geral de combinação antes de S3.

SPRAGUE e BRYAN (32) e MEZZACAPPA (33) observaram haver segregação durante o processo de homogeneização das linhagens até S3 - S4.

Uma vês obtidas as melhores linhagens, devemos testar, em S5 a capacidade específica de combinação, para que as linhas eleitas sejam associadas em híbridos simples.

\section{Doce Precoce Laranja}

Nos Estados Unidos, onde o período de plantação é restrito, parecia interessante obter por autofecundação, seleção e cruzamento, uma série de híbridos de diferentes precocidades, para assim solucionar o problema do milho doce duranie tołu o verão. Assim, por exemplo, SINGLETON (13) estabeleceu um programa denominado "Breeding for a Sweet Corn Succession".

Sendo as nossas estações muito mais longas, o que possibilita o plantio desde fins de setembro até Natal, êsse processo nล̃o nos pareceu muito importante, exceto no que diz respeito à ưma intecipação na colheita do milho doce.

Verificando que o plantio antes das primeiras chuvas năo dava os resultados esperados, pois as plantas demorava!n a florescer, iniciámos novos trabalhos a fim de obter uma vamedide precoce; sabendo, ainda, que o mercado dá preferência a espicas colcridas, procuramos obter um novo tipo de milh.1 doce, alaraniedo e precoce, por meis de cruzamentos de P-1.3, com Quarentão e Colorado Estanzuela, introduzidos em 1945 e desde então em estudo em nossa Secção.

Us descendentes dêsses cruzamentos foram selecionacios e sutofocundados e possuimos, hoje, algumas linhagens de mi!ho doce precoce laranja com planta e espigas com bôas características agronômicas, grãos dúces e tenros.

A maior dít aldade que temos encontrado é eliminar a tendêr.cia para formar pseudo-açúcares, pois como já mencionamos parece baver correlaçäo entre a coloração laraajંz $e$ pseudo-doce.

Firam felt:s top-crosses ras diversas linhagens pata se conhecer a capacidade de combinação. 
Ainda, êste ano, será testada a capacidade especifica de cumbinação a fim de que as melhores linhagens sejam associadas em híbridos simples.

\section{Mitho doce Amarelo}

Novos trabalhos de melhoramento foram iniciados em 1950, visando o aproveitamento, além da coloração amarela, de certas características desejáveis do milho dente nacional e americano.

Utilizamos nesse trabalho linhagens e variedades sintéticas de dente amarelo Pelotas, Armour, Monte Olimpo, dente amarelc indígena Yvaí, dente Americano, e cruzamentos entre dente Americano e os tipos nacionais acima referidos.

Foram feitos cêrca de 650 cruzamentos em 1950 e o material escolhido foi plantado em 1951. Este ano, os grãos doces das espigas selecionadas serão plantados a fim de serem escolhidas as melhores linhagens.

Visamos com êsse trabalho, obter novas variedades sintéticas e híbridos de coloração amarela.

Como já mencionamos, parece haver correlação entre a porcentagem de pseudo-açúcares e a coloração laranja do endosperma nos cruzamentos com raças de cateto.

Talvez não seja a coloração laranja que concorra para aumentar a porcentagem de grãos pseudo-açúcares, mas sim o endosperma duro do material usado.

Grande número de cruzamentos entre o P-18 e linhagens e variedades sintéticas de dente amarelo foi feito em 1950. issperamos assim resolver, se de fato a maior porcentagem de grãcs pseudo-açúcares é associada à coloração amarela do endosperma ou ao tipo duro ou finalmente aos dois caracteres em conjunto.

\section{RESUMO E CONCLUSÕES}

$\mathrm{Na}$ presente publicação foi feito um breve resumo dos principajs trabalhos sôbre os gens básicos para os fenótipos doce e pseudo-doce. A parte relativa ao melhoramento do milho doce, também, foi abordada. 
Do exposto podemos concluir que o melhorista, antes de inais nada deve conhecer as exigências do mercado e da lavoura, assim como, ter sempre em mente, as características desejàveis no milho doce, tais como sabor, textura dos grãos, espessura do pericarpio, etc.

\section{BIBLIOGRAFIA}

ANDREW, R. H., BRINK, R. A. and NEAL, N. P. (10) - Some effects of the waxy and sugary genes on endosperm development in maize. Jour. Agr. Res., 69: 355-371. 1944.

CULPEPPER, C. W., and MAGOON, C. A. (8) - Studies on the relative merits of sweet corn varieties for canning purposes and the relation of maturity of corn to quality of the canned product. J. Agr. Res., 28: 403-443. 1924.

DOXTATOR, C. W. (9) - Studies of quality in canning corn. Jour. Amer. Soc. Agron., 29:735-753. 1937.

DOTY, D. M., SMITH, G. M., ROACH, J. R., and SULLIVAN, J. T. (12) - The effect of storage on the chemical composition of some inbred and hybrid strans of sweet corn. Ind. Agr. Exp. Sta. Bul. 503: 31. 1945.

DAVIS, R. L. (24) - Report of the plant breeder. Puerto Rico Agr. Exp. Sta. 1927.

(27) - Maize crossing values in second generation lines. Jour. Agric. Res., vol. 48. 1934.

EMERSON, R. A., BEADLE and A. C. FRASER (1) - A summary of linkage studies in Maize. Cornell Univ. Memoir 180. 1935.

GANGSTAD, E. O., and SNELL, R. S. (11) - A practical method for quantitative evaluation of texture sweet corn inbreds and hybrids. Jour. Amer. Soc. Agron. 40: 885-893. 1948.

GALLINAT, W. C. e EVERETT, H. L. (15) - A tecnique for testing flavor in sweet corn. Agron. Jour. vol. 41, n. 9. 1949 
HOROVITZ, S. MARCHIONI, A. H., e FISHER; H. G. (2) -El factor Sux e el aumento del contenido de azucar, en e] Maiz para choclo. Anales del Instituto Fitotécnico de Santa Catalina. 3 (1941): 37-44.

HABER, E. S. (14) - Dent, flint, flour and waxy maize for improvement of sweet corn inbreds. Proc. Amer. Soc. Hort. Sci., 46: 293-294. 1945.

HAYES, H. K. (19) - Present-day problema of corn breeding. Jour. Amer. Soc. Agron., vol. 18. 1926.

HAYES, H. K. and JOHNSON, I, J. (23) - The breeding of improved lines of corn. Jour. Amer. Soc. Agron., vol. 31. 1939.

JORGENSON, L. and BREWBAKER, H. E. (21) - The improvement of naturally cross-pollinated plants by selection in self-fertilized lines. II. The testing and utilization of inbred strains of corn. Conn. Agric. Exp. Sta. 1935.

JENKINS, M. T. (22) - Correlation studies with inbred and crossbred strains of maize. Jour. Agric. Res., vol. 39. 1939.

JENKINS, M: T. and BRUNSON, A. M. (25) - Methods of testing inbred lines of Golden Bantam sweet corn. Jour. Amer. Soc. Agron., vol. 24. 1932.

JOHNSON, I. J. and HAYES, H. K. (26) - The combining ability of inbred lines of Golden Batam sweet corn. Jour. Amer. Soc. Agron., vol. 28. 1936.

JENKINS, M. T. (28) - The effect of inbreeding and of slection within inbred lines of maize upon the hybrids made after sucessive generations of selfing. Iowa State Col. Jour. Sci., vol. 9. 1935.

KIESSELBACH, T. A. (16) - Corn Investigations. Res. Bull. Neb. Agric. Exp. Sta., n. 20. 1922.

NiEZZACAPPA, M. P. (33) - Estudo da capacidade geral de combinação em Milho Catêto. Tése para doutoramento, a- 
presentada à Escola S. A. "Luiz de Queiroz", da Universidade de S. Paulo, em 30 de Outubro de 195.

MANGELSDORF, P. C. and R. G. REEVES (3) - The origem of indian corn and its relatives. Texas Agric. Exp. Sta. Bull. n. 574. 1939.

MANGELSDORF, P. C. (4) - The inheritance of amylaceous sugary endosperm and its derivatives in Maize. Genetics, 32: 448-458. 1947.

MATSURA, H. (5) - Tokyo Imperial University, 1929.

NILSSON-LEISSNER, G. (20) - Reltion of selfed strains of corn to F1 crosses between them. Jour. Amer. Soc. Agron., vol. 19. 1927.

RICHEY, F. D. (17) - Effects of selection on the yeld of a cross between varieties of corn. Bull. U. S. Dept. Agric., n. 1209. 1924.

RICHEY, F. D. and MAYER, L. S. (18) - The productiveness of successive generations of self-fertilized lines of corn and crosses between them. Bull. U. S. Dept. Agric., n. 1354. 1925. RICHEY, F. D. (30) - Advances in Genetics, vol. 3 - 1950. 